\title{
Development of a Mobile Application for Acquiring Clinical and Laboratorial Skills and Abilities in Pediatric Dentistry and Orthodontics
}

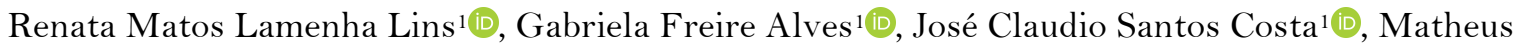 \\ Santos Mafra Barbosa ${ }^{1}$, Caio Barbosa Vieira da Silva ${ }^{2}$, Jovenildo Wanderley Santos ${ }^{3} \oplus$, Daniela \\ Maria Carvalho Pugliesi1(1), Valdeci Elias Santos Junior'1[
}

\footnotetext{
${ }^{1}$ Department of Pediatric Dentistry, Faculty of Dentistry, Federal University of Alagoas, Maceió, AL, Brazil.

${ }^{2}$ TecGraf, Pontifical Catholic University of Rio de Janeiro, Rio de Janeiro, RJ, Brazil.

${ }^{3}$ Department of Orthodontics, Faculty of Dentistry, Federal University of Alagoas, Maceió, AL, Brazil.
}

Author to whom correspondence should be addressed: Renata Matos Lamenha Lins, Department of Pediatric Dentistry, Faculty of Dentistry, Federal University of Alagoas, Av. Lourival Melo Mota, S/N Tabuleiro do Martins, Maceió, Alagoas, Brazil. Phone: +55 829961442 12. E-mail: renatamlamenha@gmail.com.

Academic Editors: Alessandro Leite Cavalcanti and Wilton Wilney Nascimento Padilha

Received: 16 September 2019 / Accepted: 29 April 2020 / Published: 23 May 2020

\begin{abstract}
How to cite this article: Lins RML, Alves GF, Costa JCS, Barbosa MSM, Silva CBV, Santos JW, et al. Development of a mobile application for acquiring clinical and laboratorial skills and abilities in pediatric dentistry and orthodontics. Pesqui Bras Odontopediatria Clín Integr. 2020; 20:e5136. https://doi.org/10.1590/pboci.2020.088
\end{abstract}

\begin{abstract}
Objective: To develop an educational mobile application as a dynamic platform provided free of charge, including several clinical and laboratory protocols for a wider range of skills and greater knowledge on the strategic axes of child dental care: Pediatric Dentistry and Orthodontics. Material and Methods: The prototype tool was structured as follows: development of clinical and laboratory contents to be addressed, software selection, layout format, inclusion of features, applicability and acceptability tests of the operational system, and indexation on the Play Store ${ }^{\circledR}$ application store (free of charge). Results: The mobile application has shown to be a tool capable of storing and providing data through various audiovisual media formats on clinical and laboratory contents of child dental care. Media resources were developed for the following themes: restorative dentistry in pediatric dentistry, radiographic techniques with pediatric patients, pulp therapy in deciduous teeth, traumatic injuries in the primary dentition, and preventive and interceptive orthodontics. The short-duration multimedia content, with different audiovisual formats, proved to be coherent with the peculiarities of each procedure, enabling to better visualize and understand the techniques. Moreover, the rewind, fast forward, and pause features were included in the mobile application, as well as the possibility of saving print screens, as well as highlighting and searching for contents of interest. Conclusion: The OdontoPed-Helpbox ${ }^{\circledR}$ demonstrated to be able to reach new strategies for the dynamic teaching-learning process, through operational efficiency. It proved to be a useful and instant tool for providing information to support clinical decision making in Dentistry.
\end{abstract}

Keywords: Mobile Applications; Telemedicine; Pediatric Dentistry; Orthodontics. 


\section{Introduction}

The innovation process in education, when well-structured, can fill gaps that could only be previously filled by traditional and linear teaching methods, thus enabling to improve communication, creation, and learning [1]. Technological tools and devices have been playing an increasingly fundamental role in health sciences, being able to contribute to the dynamic process of teaching-learning and act as a method of social and educational transformation, compatible with current prospects and with the evolving profile of the population $[1,2]$.

The use of Information and Communication Technology (ICT) for modeling the teaching-learning process through educational audiovisual contents has proved to efficiently interact, collaborate and develop new forms of knowledge, increasing the autonomy of users and enabling them to play an active role in their learning process [2-4].

In Dentistry, the increasing use of smartphone applications has enhanced the diagnosis and clinical decision-making process, through instant access to digital platforms [5,6]. Several studies have demonstrated the development and effectiveness of mobile applications in different areas, such as in oral health education [7,8], in the diagnosis of oral cancer [9], endodontic complications [5], and as a training tool for oral and maxillofacial surgery [6].

Although throughout their university degree, students may identify deficiencies in the diagnosis of certain pathologies and their respective therapeutic approaches in pediatric patients [10], the availability of digital tools in the area of child dental care is still scarce. With this in mind, this study aimed to develop an educational mobile application, OdontoPed-Helpbox ${ }^{\circledR}$, as a dynamic platform provided free of charge, including the main clinical and laboratory protocols for acquiring a multitude of skills in both structuring axes of child dental care: Pediatric Dentistry and Orthodontics.

\section{Material and Methods}

Study Location

The mobile application OdontoPed-Helpbox ${ }^{\circledR}$ was developed in the Faculty of Dentistry of the Federal University of Alagoas, in the city of Maceió, Brazil. The content selected for its development included clinical and laboratory protocols on the subject of child dental care, consisting of Pediatric Dentistry and Orthodontics.

\section{Pilot Study}

The prototype was developed in a structured manner, according to the following steps: content development, software selection, layout format, insertion of features, applicability and acceptability tests of the operational system, indexation, and free availability on the Play Store ${ }^{\circledR}$ application store.

\section{Content Development}

The selection of subjects to be included in the application preferably comprised contents regarding the clinical routine of ambulatory care in the field of child dental care. Therefore, the following subjects were explored: restorative dentistry in pediatric dentistry, radiographic techniques with pediatric patients, pulp therapy in deciduous teeth, traumatic injuries in the primary dentition, as well as preventive and interceptive orthodontics. Besides, topics related to the production of preventive and interceptive orthodontic appliances 
were also developed. All protocols were established according to systematic reviews of international guidelines based on high-level scientific evidence [11-17].

Each subject was assessed in conceptual and creative terms to reach an ideal educational content for each type of protocol. Therefore, different image and video processing techniques were explored, such as the use of slides, videos, hybrid images, and stop motion, as well as slow-motion and fast-motion videos. It was idealized that each produced media had a short period of execution, and a neutral and dark background was selected for their production. All photographs and videos were edited using Adobe Photoshop ${ }^{\circledR}$ and Adobe Premiere ${ }^{\circledR}$ software, respectively.

\section{Layout Format and Inclusion of Features}

The layout of the application was developed using Adobe Illustrator ${ }^{\circledR}$ software. The logo, brand, objects, and shapes of the mobile application were designed so to enable to resize of the images without any loss of quality, due to the wide range of scales available in current smartphones.

The application was developed in native Android, using Java (back-end) and XML (front-end) as the programming language. The program used was Android Studio ${ }^{\circledR}$. YouTube ${ }^{\circledR}$ (video reproduction) and Firebase $^{\circledR}$ (database) were used as external APIs (Application Programming Interfaces).

The layout was based on the educational classification of the constituting axes of the subject of child dental care, i.e., Pediatric Dentistry and Orthodontics. The respective subjects were subsequently listed in tabs containing the protocols in the formats of videos and texts, to enable on-line or off-line access. Moreover, links were also added to the layout, enabling the user to mark the content as favorite and access the media content in the search area.

\section{Applicability Tests of the Operational System}

Functionality and acceptability tests were carried out in the mobile application. Until its final version, all structuring and functional elements were duly tested until an acceptable version was obtained, without any predicted instabilities, such as tab, resize and/or interface inefficiencies. Therefore, cyclical usability testing was performed based on system error codes. For this purpose, each feature was tested on the system layout and interface with Youtube $^{\circledR}$ and Firebase ${ }^{\circledR}$. Also, possible mistakes on the layout were verified using different smartphone screen sizes.

\section{App Indexing}

The OdontoPed-Helpbox ${ }^{\circledR}$ application, in its 1.0 version, was finalized and indexed on Play Store ${ }^{\circledR}$, available free of charge (https://play.google.com/store/apps/details?id=sam.gurio.odontoapp).

\section{Results}

The OdontoPed-Helpbox ${ }^{\circledR}$ application proved to be a tool capable of storing and providing data using audiovisual media contents on clinical and laboratory subjects of child dental care, being indexed on Play Store $^{\circledR}$. Table 1 shows the contents developed regarding each specialization involved in child dental care. The layout and operational system of the mobile application are shown in Figure 1.

The content was reproduced using the most suitable audiovisual formats, considering the particularities of each procedure, and aiming at better visualizing and understanding each technique. Figure 2 
shows the clinical protocol of pulpectomy in deciduous teeth, according to the instrumentation technique.

Figure 3 illustrates a Nance appliance produced in the laboratory for mixed dentition.

Table 1. Specialization, procedure and duration of media content produced.

\begin{tabular}{llc}
\hline \multicolumn{1}{c}{ Specialization } & \multicolumn{1}{c}{ Procedure } & Duration \\
\hline Restorative Dentistry & Rubber dam isolation & $1: 47$ \\
& Sealants & $1: 13$ \\
& Biological restoration & $2: 41$ \\
& Stainless steel crown & $2: 56$ \\
Radiology & Radiographic techniques & $6: 11$ \\
Endodontics & Coronary opening of incisor, canine, upper and & $5: 13$ \\
& lower molar deciduous teeth & $0: 32$ \\
& Indirect pulp capping & $0: 54$ \\
& Direct pulp capping & $0: 57$ \\
& Pulpectomy with MTA/CH & $0: 54$ \\
& Pulpectomy with formocresol & $1: 59$ \\
& Pulpectomy with CH & $0: 53$ \\
Traumatic Injuries in the Primary Dentition & Pulpectomy with CTZ & Trauma to the soft tissues \\
& Trauma to the supporting tissues & $3: 07$ \\
Preventive and Interceptive Orthodontics & Band and loop & $5: 10$ \\
& Nance appliance & $5: 13$ \\
& Orthodontic retainer & $3: 56$
\end{tabular}

\section{OPERATION}

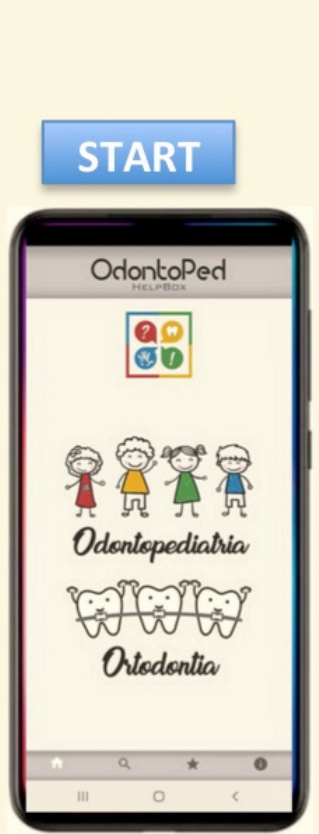

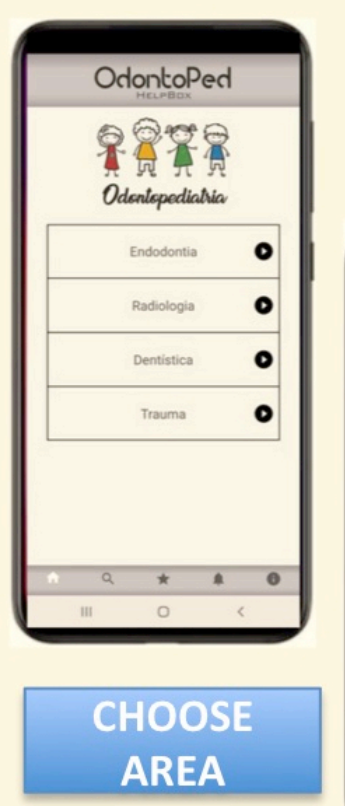

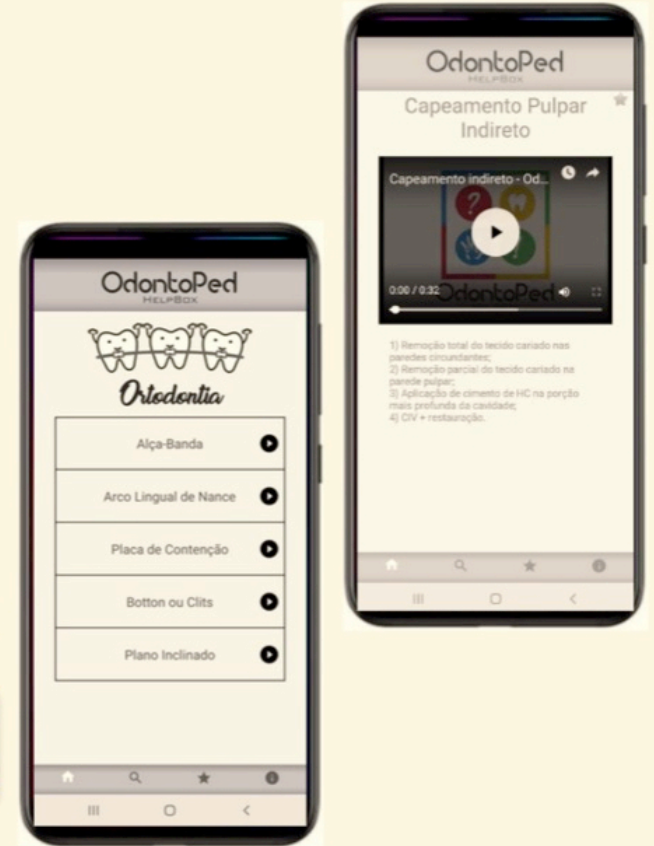

WATCH AND

STUDY

Figure 1. Layout and operational system of the OdontoPed-Helpbox ${ }^{\circledR}$ application. 

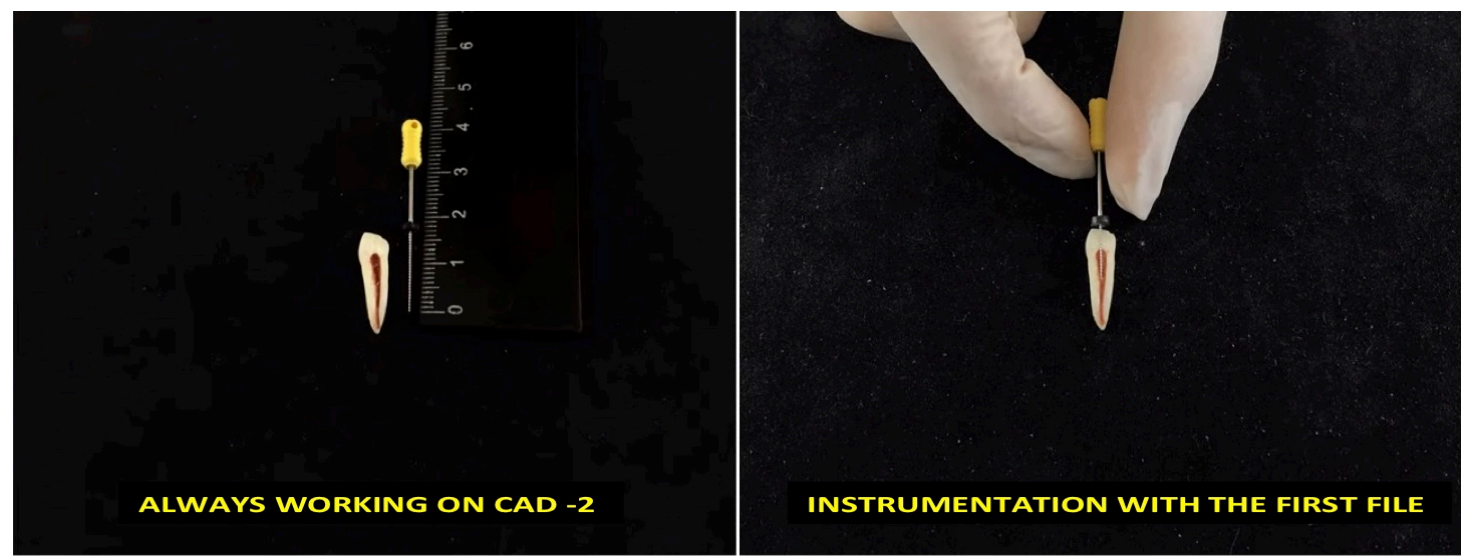

CALCIUM HYDROXIDE PULPECTOMY I OdontoPed HeIPBox

CALCIUM HYDROXIDE PULPECTOMY I OdontoPed HelpBox

Figure 2. Video produced in stop motion for the technique of pulpectomy in deciduous teeth. CAD: Apparent Tooth Length; HC: Calcium Hydroxide.

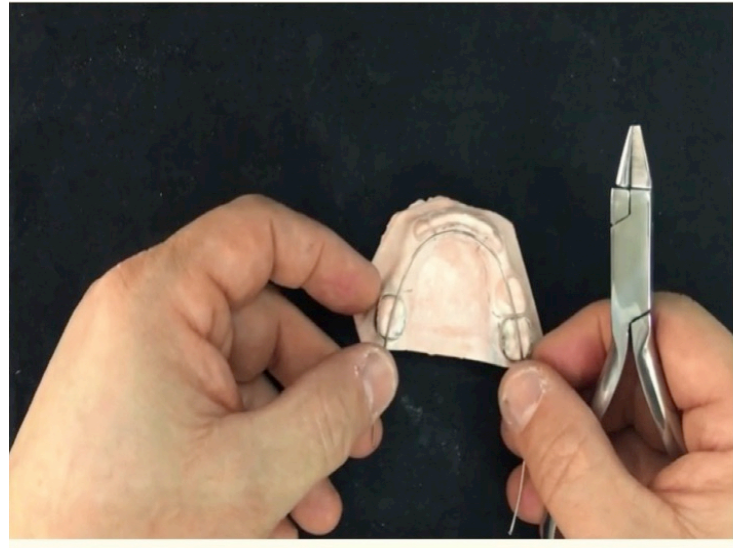

NANCE LINGUAL ARCH I OdontoPed HelpBox

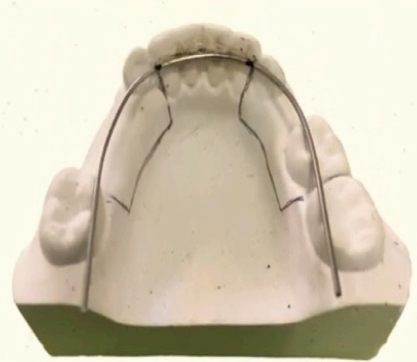

PARABOLA ASPECT

NANCE LINGUAL ARCH I OdontoPed HelpBox

Figure 3. Fast motion video to produce a Nance appliance in mixed dentition.

\section{Discussion}

This study enabled to adapt the educational content of the structuring axes of the subject of child dental care, Pediatric Dentistry and Orthodontics, to the current Information and Communication Technologies (ICT), exploring the use of mobile applications for smartphones. The results found demonstrated dynamic and educational media resources for easy access to the clinical and laboratory contents of the discipline.

Studies carried out with undergraduate students have shown the difficulties found by students in obtaining theoretical and practical content related to child dental care [10,18]. The constant biological development to which the child is subject and the particularities inherent to the pediatric physiological and anatomical constitution seem to be related to the barriers encountered by the students in the better visualization and understanding of the approaches directed at the infant patient [10].

The longevity of the acquired knowledge is significantly affected according to the learning process with which it is related [10]. Mobile learning comes from the interrelation between portable technology (use of mobile communication devices) and e-learning (learning facilitated and mediated by computing information 
and communication) [19], and has shown promising results as support in the transmission of knowledge in health sciences [3-9,20].

In the present study, the sequenced simulation of the clinical and laboratory protocols of child dental care demonstrated; as a result, dynamic and educational media resources with a short reproduction period, based on current international guidelines with high scientific evidence [11-17]. In the field of oral and maxillofacial surgery, previously developed applications have shown effectiveness in their reach through the quick and easy availability of protocols and therapeutics pertinent to their use, as well as guidelines to technical approaches and better visualization of the biological structures involved [6], characteristics displayed in this pediatric tool developed.

Besides, in this study, it was possible to address aspects related to traumatic injuries in supporting and soft dental tissues of primary teeth, according to the guidelines established by the International Association of Dental Traumatology (IADT) [16]. For each type of traumatic injury, it was combined its simulation in a model, descriptions relevant to the related clinical and radiographic findings, clinical case in high definition of the lesion, the respective treatment, follow-up procedures, and outcome. In a recent study, the use of mobile applications as support tools for clinical decision-making in dental trauma demonstrated effectiveness for dentistry students and experienced pediatric dentists [20].

However, since clinical interventions for dental trauma require prompt performance by the professional, the difficulty of handling the applications currently available for the topic can act to impair the accuracy of emergency care [20]. Also, visual pollution from commercial advertisements and the insufficient amount of information on the diagnosis and treatment of traumatic injuries have been reported as harmful to the functionality of such applications, leading to the installation of various mobile applications by the user [21]. In order to avoid such disturbances, the mobile application developed in this study offers fast and practical access to the user, as well as content relevant to the main clinical themes that involve the care of infant patients. In addition, the OdontoPed-Helpbox ${ }^{\circledR}$ tool was developed for exclusively academic purposes, thus excluding any possibility of pop-ups that may harm the transmission of content to the user.

The incorporation of methods that have proven to benefit learning in educational technologies for the continuous development of health professionals consists of one of the essential pillars, based on evidence, for the effectiveness of the ICT applied [3]. Considering this, the use of audiovisual resources has been widely explored due to its wide teaching capacity, resulting from the ability to retain the individual's attention [22]. The mobile application developed in this study offers the user the possibility to move back, forward, and pause the chosen media, save screen images, highlight, and search the contents, favoring the repetition of their access and reproduction. This type of handheld technology has not only demonstrated to be a successful learning support tool, but it has also shown the potential of transforming how individuals can learn and interpret the knowledge acquired [23].

Some limitations can be identified regarding the present study. Since specific platforms for child dental care are scarce in the scientific literature, the comparative analysis regarding the development of this mobile application with other available tools has not been verified. The indexing of OdontoPed-Helpbox ${ }^{\circledR}$ to only one mobile application store makes its access exclusive to Android ${ }^{\circledR}$ smartphone users, which, although covers a large part of the population, does not reach all potential users. Thus, it is suggested that future versions of the application include a greater variety of virtual stores, in order to democratize the acquisition of the platform. Besides, future studies that assess the impact of the tool on the acquisition or improvement of knowledge are necessary, aiming at optimizing the theoretical and/or practical evolution of its future versions. 


\section{Conclusion}

The OdontoPed-Helpbox ${ }^{\circledR}$ demonstrated to be able to reach new strategies for the dynamic teachinglearning process through operational efficiency. It proved to be a useful and instant tool for providing information to support clinical decision making in Dentistry.

\section{Authors' Contributions}

\begin{tabular}{|c|c|c|}
\hline RMLL & (iD) $0000-0002-2968-6849$ & $\begin{array}{l}\text { Conceptualization, Methodology, Investigation, Resources, Data curation, Writing } \\
\text { - Original Draft Preparation, Writing - Review and Editing, Visualization, } \\
\text { Supervision, Project administration. }\end{array}$ \\
\hline GFA & (iD) $0000-0002-5351-3278$ & Conceptualization, Methodology, Investigation, Resources, Data curation. \\
\hline JCSC & (iD) $0000-0001-5225-0843$ & Conceptualization, Methodology, Investigation, Resources, Data curation. \\
\hline MSMB & (iD) $0000-0001-6728-4229$ & Conceptualization, Methodology, Investigation, Resources, Data curation. \\
\hline CBVS & (iD) $0000-0003-4288-3713$ & Methodology, Software, Validation, Formal analysis, Investigation, Data curation. \\
\hline JWS & (iD) $0000-0002-7307-2182$ & Conceptualization, Methodology, Investigation, Resources, Data curation. \\
\hline DMCP & (iD) $0000-0002-7854-0416$ & Conceptualization, Methodology, Investigation, Resources, Data curation. \\
\hline VESJ & (iD) $0000-0001-9748-5830$ & $\begin{array}{l}\text { Conceptualization, Methodology, Software, Formal Analysis, Investigation, } \\
\text { Resources, Data curation, Writing - Original Draft Preparation, Writing - Review } \\
\text { and Editing, Visualization, Supervision, Project administration. }\end{array}$ \\
\hline
\end{tabular}

\section{Financial Support}

None.

\section{Conflict of Interest}

The authors declare no conflicts of interest.

\section{References}

[1] Isaacs AN, Nisly S, Walton A. Student-generated e-learning for clinical education. Clin Teach 2017; 14(2):129-33. https://doi.org/10.1111/tct.12526

[2] Rocha TA, Fachini LA, Thumé E, Silva NC, Barbosa AC, Carmo MD, et al. Mobile health: new perspectives for healthcare provision. Epidemiol Serv Saúde 2016; 25(1):159-70. http://dx.doi.org/10.5123/s167949742016000100016

[3] Scott KM, Baur L, Barrett J. Evidence-based principles for using technology-enhanced learning in the continuing professional development of health professionals. J Contin Educ Health Prof 2017; 37(1):61-6. https://doi.org/10.1097/CEH.0000000000000146

[4] Lee MH, Wu HC, Tseng CM, Ko TL, Weng TJ, Chen YF. Health education and symptom flare management using a video-based m-health system for caring women with IC/BPS. Urology 2018; 119:62-9. https://doi.org/10.1016/j.urology.2018.05.027

[5] Oliveira MLB, Verner FS, Kamburoglu K, Silva JNN, Junqueira RB. Effectiveness of using a mobile app to improve dental students' ability to identify endodontic complications from periapical radiographs. J Dent Educ 2019; 83(8): e1e8. https://doi.org/10.21815/JDE.019.099

[6] Carey E, Payne KFB, Ahmed N, Goodson A. The benefit of the smartphone in oral and maxillofacial surgery: smartphone use among maxillofacial surgery trainees and iphone apps for the maxillofacial surgeon. J Maxillofac Oral Surg 2015; 14(2):131-7. https://doi.org/10.1007/s12663-013-0550-3

[7] Scheerman JFM, van Meijel B, van Empelen P, Verrips GHW, van Loveren C, Twisk JWR, et al. The effect of using a mobile application ('WhiteTeeth') on improving oral hygiene: a randomized controlled trial. Int J Dent Hyg 2020; 18(1):73-83. https://doi.org/10.1111/idh.12415

[8] Lefer G, Bourdon P, Mercier C, Lopez-Cazaux S. Teaching tooth brushing to children with autistic spectrum disorder: a tablet-based training programme. Sante Publique 2018; 30(3):297-306. https://doi.org/10.3917/spub.183.0297

[9] Nayak PP, Nayak SS, Sathiyabalan D, Aditya NK, Das P. Assessing the feasibility and effectiveness of an app in improving knowledge on oral cancer: an interventional study. J Cancer Educ 2018; 33(6):1250-4. https://doi.org/10.1007/s13187-017-1239-y 
[10] Sahebalam R, Talebi M, Kazemian S, Akbari M. Natural model training, an alternative way to enhance learning in pediatric dentistry. J Dent 2014; 11(5):531-5.

[11] American Academy of Pediatric Dentistry. Guideline on Pediatric Restorative Dentistry. Pediatr Dent 2012; 34(5):173-80.

[12] Chisini LA, Collares K, Cademartori MG, Oliveira LJC, Conde MCM, Demarco FR, et al. Restorations in primary teeth: a systematic review on survival and reasons for failures. Int J Paediatr Dent 2018; 28(2):123-39. https://doi.org/10.1111/ipd.12346

[13] American Academy of Pediatric Dentistry. Guideline on Pulp Therapy for Primary and Immature Permanent Teeth. Pediatr Dent 2016; 38(6):280-8.

[14] Coll JA, Seale NS, Vargas K, Marghalani AA, Al Shamali S, Graham L. Primary tooth vital pulp therapy: a systematic review and meta-analysis. Pediatr Dent 2017;39(1):16-123.

[15] American Academy of Pediatric Dentistry. Prescribing dental radiographs for infants, children, adolescents, and individuals with special health care needs. Pediatr Dent 2017; 39(6):205-7.

[16] Diangelis AJ, Andreasen JO, Ebeleseder KA, Kenny DJ, Trope M, Sigurdsson A, et al. International Association of Dental Traumatology. International Association of Dental Traumatology guidelines for the management of traumatic dental injuries: 1. Fractures and luxations of permanent teeth. Dent Traumatol 2012; 28(1):2-12. https://doi.org/10.1111/j.1600-9657.2011.01103.x

[17] Cohenca N. International Association for Dental Traumatology. Traumatic Dental Injuries: Adherence to Treatment Guidelines Critical to Positive Patient Outcomes. Rev Assoc Paul Cir Dent 2016; 70(4): 386-97.

[18] Rock WP, O'Brien KD, Stephens CD. Orthodontic teaching practice and undergraduate knowledge in British dental schools. Br Dent J 2002; 192(6):347-51. https://doi.org/10.1038/sj.bdj.4801371

[19] Istepanian RSH, Al-Anzi T. m-Health 2.0: New perspectives on mobile health, machine learning and big data analytics. Methods 2018; 151:34-40. https://doi.org/10.1016/j.ymeth.2018.05.015

[20] Machado JP, Lam XT, Chen JW. Use of a clinical decision support tool for the management of traumatic dental injuries in the primary dentition by novice and expert clinicians. Dent Traumatol 2018; 34(2):120-8. https://doi.org/10.1111/edt.12390

[21] Djemal S, Singh P. Smartphones and dental trauma: the current availability of apps for managing traumatic dental injuries. Dent Traumatol 2016; 32:52-7. https://doi.org/10.1111/edt.12217

[22] Soubra BN, Debs NN. Impact of audiovisual method in educating children facing dental avulsion. Dent Traumatol 2014; 30(3):216-21. https://doi.org/10.1111/edt.12086

[23] Saljo R. Digital tools and challenges to institutional traditions of learning: technologies, social memory and the performative nature of learning. J Comput Assist Lear 2010; 26(1):53-64.

https://doi.org/10.1111/j.1365-2729.2009.00341.x 